\title{
DEGRADAÇÃO DA COR E DO ÁCIDO ASCÓRBICO NA DESIDRATAÇÃO OSMÓTICA DE KIWI*
}

\author{
BOGDAN DEMCZUK JUNIOR** \\ DIANATHOMÉ FACHIN ${ }^{* * *}$ \\ ROSEMARY HOFFMANN RIBAN ${ }^{* * * *}$ \\ RENATO JOÃO SOSSELADE FREITAS*****
}

\begin{abstract}
No presente trabalho estudou-se a degradação da cor e do ácido ascórbico em kiwis processados por desidratação osmótica. Os frutos, submetidos a três pré-tratamentos químicos (cloreto de cálcio, ácido cítrico e ácido ascórbico) foram desidratados em solução de sacarose a $50^{\circ}$ Brix por 150 minutos em banho termostático a $40^{\circ} \mathrm{C}$ sob agitação a $70 \mathrm{rpm}$. As reações de degradação dos parâmetros $a^{*}$ e da variação total de cor (Ä $\left.E^{*}\right)$ foram melhor ajustadas ao modelo cinético de primeira ordem. O pré-tratamento com cloreto de cálcio ocasionou melhor manutenção da cor verde das fatias durante o processo. Os teores de vitamina C apresentaram redução média de $40 \%$ até o final da desidratação. Os tratamentos com ácido cítrico e ácido ascórbico proporcionaram a manutenção de níveis mais elevados de vitamina C nas fatias de kiwi.
\end{abstract}

PALAVRAS-CHAVE: KIWI; DESIDRATAÇÃO OSMÓTICA; COR; ÁCIDO ASCÓRBICO, DEGRADAÇÃO.

* Parte da dissertação de mestrado do primeiro autor.

** Mestre em Tecnologia de Alimentos, Programa de Pós-Graduação em Tecnologia de Alimentos, Universidade Federal do Paraná (UFPR), Curitiba, PR (e-mail: bdjunior@gmail.com).

*** Doutora em Food Technology, Pontifícia Universidade Católica do Paraná, Curitiba, PR (e-mail: diana.fachin@pucpr.br).

*** Doutora em Alimentos e Nutrição, Professora do Programa de Pós-Graduação em Tecnologia de Alimentos, UFPR, Curitiba, PR (e-mail: ribani@ufpr.br).

***** Doutor em Química, Professor do Programa de Pós-Graduação em Tecnologia de Alimentos, UFPR, Curitiba, PR (e-mail: rfreitas@brturbo.com.br). 


\section{INTRODUÇÃO}

Fruto originário da Ásia, o kiwi foi recentemente introduzido no mercado brasileiro, o que pode explicar em parte o seu baixo consumo para o qual contribui também o custo elevado (TRICHES e SEBBEN, 2004; BUCHWEITZ, 2005). O fruto, rico em vitamina C, minerais e fibras tem polpa colorida e atrativa (SOUZA, MARODIN e BARRADAS, 1996; MOTOHASHI et al., 2002).

O consumo de frutas é valorizado pelos benefícios à saúde e pela contribuição para a melhoria da qualidade de vida. A necessidade do mercado consumidor por produtos convenientes ocasionou 0 surgimento de cadeias de fast food, levando ao consumidor alimentos pobres em fibras, vitaminas e minerais e ricos em sal, gordura e açúcar. Um dos reflexos desses hábitos alimentares ficou aparente no aumento da incidência da obesidade e de doenças cardiovasculares. Depois dessa fase o consumidor passou a ter acesso a alimentos ao mesmo tempo convenientes e saudáveis (VILAS BOAS, 2002).

A desidratação osmótica, processo brando de conservação, pode ser aplicada em frutas mantendo a sua integridade estrutural, nutricional e funcional. Tal processo é capaz de remover parte da água por imersão do alimento em solução hipertônica (GOULARTE, ANTUNES e ANTUNES, 2000; KOWALSKA e LENART, 2001).

A qualidade nutricional e a aparência de alguns alimentos são fatores relevantes durante 0 processamento (IBARZ, PAGÁN e GARZA, 1999). O ácido ascórbico (vitamina C) constitui importante componente nutricional, sendo também utilizado como aditivo em muitos alimentos devido à sua capacidade antioxidante (LARISCH, GROB e PISCHETSRIEDER, 1998). Entretanto, tratando-se composto instável o ácido ascórbico decompõe-se facilmente (FENEMA, 1996; LEE e COATES, 1999). A degradação do ácido ascórbico ocorre tanto aeróbica quanto anaerobicamente e está ligada a fatores como oxigênio, calor, luminosidade, temperatura e tempo de armazenagem (GORDON e SAMANIEGO-ESGUERRA, 1990; JOHNSON, BRADDOCK e CHEN, 1995).

As espécies de frutas contêm diferentes tipos de pigmentos que podem de alguma forma influenciar a degradação da cor. Os parâmetros colorimétricos $L^{*}, a^{*} e b^{*}$ e a diferença total de cor (ÄE*) têm sido usados na determinação da vida-de-prateleira de frutas em pedaços (KLUTER et al., 1994) e no cálculo de perda de cor durante o processamento de polpas de frutas em diferentes temperaturas (LOZANO e IBARZ, 1997).

O presente trabalho teve como objetivo avaliar as variações do ácido ascórbico (vitamina C) e da cor instrumental de kiwis pré-tratados quimicamente e desidratados por osmose.

\section{MATERIAL E MÉTODOS}

\subsection{MATERIAL}

Kiwis da cultivar Monty, adquiridos em pomar comercial localizado no município de Fernandes Pinheiro (PR) e acondicionados em caixas plásticas fenestradas, foram armazenados em refrigerador a temperatura de $4^{\circ} \mathrm{C}$ por até 3 semanas. A solução desidratante utilizada foi preparada com sacarose comercial e água destilada na concentração de $50^{\circ}$ Brix. Como preservantes químicos foram utilizados cloreto de cálcio, ácido cítrico e ácido ascórbico, todos de grau analítico (marca Synth).

\subsection{MÉTODOS}

\subsubsection{Procedimento experimental}

Os frutos foram selecionados considerando-se como critério a uniformidade do lote com relação ao tamanho e formato. Foram utilizados kiwis com teor de sólidos solúveis de aproximadamente 
9, $0^{\circ}$ Brix. Depois de pré-lavados e desinfetados, os frutos foram descascados manualmente e fatiados (aproximadamente $1 \mathrm{~cm}$ de espessura) com facas inoxidáveis, conforme CARVALHO e LIMA (2002). As fatias foram separadas em 4 grupos correspondentes aos pré-tratamentos. As fatias de kiwi foram imersas por 5 min em solução de cloreto de cálcio a 1\%, solução de ácido ascórbico a 1\%, solução de ácido cítrico a $1 \%$ (correspondentes aos tratamentos) e o controle imerso em água destilada. Os kiwis foram drenados em peneira durante 2 min e retiradas as amostras para análises físico-químicas de cada tratamento, sendo essa etapa considerada como o tempo 0 (zero) de desidratação osmótica.

Para cada pré-tratamento realizou-se a pesagem de, aproximadamente, $120 \mathrm{~g}$ de kiwi em cestos de polietileno $(15 \times 11 \mathrm{~cm}) \mathrm{com}$ abertura de malha de 2 milímetros. Cada cesto foi disposto num copo de Béquer com capacidade de $1000 \mathrm{~mL}$, conforme metodologia modificada de MARTIM (2006).

A solução osmótica, previamente aquecida na temperatura de operação, foi adicionada aos copos de Béquer na proporção fruta:solução $(\mathrm{m} / \mathrm{m})$ de 1:4. Os recipientes foram posicionados em banho a $40^{\circ} \mathrm{C}$ e mantidos sob agitação a $70 \mathrm{rpm}$ durante $150 \mathrm{~min}$. Depois de decorrido o tempo para cada amostragem retirava-se o copo de Béquer correspondente em intervalos pré-estabelecidos (15, $30,45,60,90,120$ e $150 \mathrm{~min}$ ). Retirava-se também o cesto da solução osmótica, sendo as fatias drenadas em peneira por 1 min e enxaguadas rapidamente com $100 \mathrm{~mL}$ de água destilada. Para remoção da solução superficial, as fatias foram dispostas sobre papel absorvente por 2 min, adaptandose o procedimento adotado por BUCHWEITZ (2005).

\subsubsection{Caracterização das amostras}

Para determinação do teor de sólidos solúveis do kiwi utilizou-se refratômetro de bancada (RL3 - Polskie Zaklandy Optyczne S. A.) com escala de 0 a $90^{\circ}$ Brix e correção da temperatura para $20^{\circ} \mathrm{C}$, conforme método ${ }^{\circ}$ 13.6.1 do IAL (1985).

Determinou-se o teor de umidade das amostras por gravimetria a $105^{\circ} \mathrm{C}$ durante $24 \mathrm{~h}$ em estufa até peso constante, conforme método $\mathrm{n}^{\circ} 4.5 .1$ do IAL (1985).

Quantificou-se a acidez total titulável das amostras de kiwi por titulação com solução padronizada de hidróxido de sódio, utilizando solução alcoólica de fenolftaleína a 1\% como indicador de acordo com o método $n^{\circ}$ 13.6.2 do IAL (1985). Os resultados foram expressos em porcentagem de ácido cítrico.

Os valores de atividade de água $\left(a_{w}\right)$ das amostras de kiwi foram determinados em higrômetro digital marca Aqualab série 3TE (DECAGON DEVICES, 2007).

\subsubsection{Análise instrumental de cor}

A variação nos parâmetros de cor foi determinada utilizando-se espectrofotômetro Hunter Lab Mini Scan XE Plus (Reston, VA, EUA). O instrumento, equipado com iluminante $\mathrm{D}_{65} / 10^{\circ}$ foi calibrado com placa preta e cerâmica-padrão branca $(X=78,9, Y=83,9, Z=88,9)$. A variação no eixo $L^{*}$ representa as mudanças na luminosidade com faixa de 0 (preto) a 100 (branco). O parâmetro $a^{\star}$ expressa a variação no eixo verde/vermelho (-a*/a*) e o parâmetro $b^{\star}$ a variação no eixo azul/amarelo $\left(-b^{\star} / b^{*}\right)$.

A diferença total de cor (ÄE*) foi determinada pela Equação 1 (HUNTERLAB, 1996):

$$
\Delta E^{*}=\left[\left(\Delta L^{*}\right)^{2}+\left(\Delta a^{*}\right)^{2}+\left(\Delta b^{*}\right)^{2}\right]^{\frac{1}{2}}
$$

Em que: $\ddot{A}$ = diferença entre cada parâmetro de cor da amostra inicial e a amostra em determinado tempo de processo.

\subsubsection{Teor de vitamina C}

Determinou-se o teor de ácido ascórbico (vitamina C) por volumetria de oxi-redução e titulação das amostras com solução 2,6-diclofo-fenol indofenol-sódico (DCFI), segundo método 43.056 da AOAC (1984). 


\subsubsection{Análise estatística dos dados}

Todas as análises físico-químicas foram realizadas em triplicata, sendo os resultados obtidos submetidos à análise de variância (ANOVA) e a diferença estatística das médias ao teste de Tukey (nível de $5 \%$ de significância), utilizando-se o programa MSTATC (MICHIGAN STATE UNIVERSITY, 1989). A representação gráfica dos valores e os ajustes dos pontos foram obtidos com o auxílio do programa Statistica versão 7 .

\subsubsection{Parâmetros cinéticos}

A meia-vida, definida como o tempo necessário para a redução do valor inicial do parâmetro avaliado, foi determinado conforme a equação citada por SINGH (1996), que utiliza como base a constante de reação.

\section{RESULTADOS E DISCUSSÃO}

A Tabela 1 apresenta a caracterização físico-química das amostras de kiwi in natura e as variações ocorridas após as fatias sofrerem imersão nas soluções correspondentes aos pré-tratamentos.

\section{TABELA 1 - COMPARAÇÃO ENTRE AS CARACTERÍSTICAS FÍSICO-QUÍMICAS DAS FATIAS DE KIWI IN NATURA E PRÉ-TRATADAS QUIMICAMENTE}

\begin{tabular}{cccccc}
\hline PARÂMETROS & \multicolumn{4}{c}{ PRÉ-TRATAMENTO $^{(1)}$} \\
\cline { 2 - 6 } & KIWI IN NATURA & AD & CC & AC & AA \\
\hline $\begin{array}{c}\text { Sólidos solúveis totais } \\
\left({ }^{\circ} \text { Brix) }\right.\end{array}$ & $9,00^{\mathrm{a}}$ & $8,80^{\mathrm{a}}$ & $9,17^{\mathrm{a}}$ & $8,83^{\mathrm{a}}$ & $9,07^{\mathrm{a}}$ \\
\hline Umidade $(\%)$ & $87,22^{\mathrm{a}}$ & $88,12^{\mathrm{a}}$ & $87,98^{\mathrm{a}}$ & $87,83^{\mathrm{a}}$ & $88,22^{\mathrm{a}}$ \\
\hline $\begin{array}{c}\text { Acidez total titulável }(\mathrm{g} \text { de } \\
\text { ácido cítrico/100 g) }\end{array}$ & $1,80^{\mathrm{a}}$ & $1,80^{\mathrm{a}}$ & $1,85^{\mathrm{a}}$ & $2,56^{\mathrm{b}}$ & $2,35^{\mathrm{b}}$ \\
\hline $\begin{array}{c}\text { Relação sólidos solúveis } \\
\text { totais/acidez total titulável }\end{array}$ & $5,00^{\mathrm{a}}$ & $5,00^{\mathrm{a}}$ & $4,86^{\mathrm{a}}$ & $3,51^{\mathrm{b}}$ & $3,82^{\mathrm{b}}$ \\
\hline Atividade de água a $25^{\circ} \mathrm{C}$ & $0,985^{\mathrm{a}}$ & $0,985^{\mathrm{a}}$ & $0,985^{\mathrm{a}}$ & $0,985^{\mathrm{a}}$ & $0,985^{\mathrm{a}}$ \\
\hline $\begin{array}{c}\text { Vitamina C }(\mathrm{mg} \text { de ácido } \\
\text { ascórbico/100 g) }\end{array}$ & $137,65^{\mathrm{a}}$ & $135,23^{\mathrm{a}}$ & $139,77^{\mathrm{a}}$ & $143,60^{\mathrm{a}}$ & $180,10^{\mathrm{b}}$ \\
\hline $\begin{array}{c}\text { Diferença total de cor } \\
\left(\Delta \mathrm{E}^{*}\right)\end{array}$ & - & $1,43^{\mathrm{d}}$ & $6,26^{\mathrm{c}}$ & $9,98^{\mathrm{a}}$ & $7,64^{\mathrm{b}}$ \\
\hline
\end{tabular}

NOTA: Letras diferentes na mesma linha indicam diferença significativa ao nível de $5 \%$ pelo Teste de Tukey. ( 1 ) valores médios de três repetições.

$\mathrm{AD}=$ Água destilada; $\mathrm{CC}=$ Cloreto de cálcio; $\mathrm{AC}=$ Ácido cítrico; $\mathrm{AA}=$ Ácido ascórbico.

O valor encontrado para umidade foi maior que $86 \%$, descrito na Tabela Brasileira de Composição dos Alimentos (TACO) em 2004. A porcentagem de ácido cítrico esteve acima da faixa de 1,22 g/100 g encontrada por BUCHWEITZ (2005), cuja diferença pode estar relacionada ao fato da matéria-prima apresentar maior teor de sólidos solúveis $\left(13^{\circ} \mathrm{Brix}\right)$. A quantidade de vitamina $\mathrm{C}$ determinada foi maior que o valor de $97,3 \mathrm{mg} / 100 \mathrm{~g}$, descrito pelo Departamento de Agricultura dos Estados Unidos (USDA, 2004).

Os teores de sólidos solúveis totais, umidade e atividade de água não diferiram estatisticamente entre si ao nível de $5 \%$ após os pré-tratamentos. Foi verificada alteração significativa $(p<0,05)$ do teor de acidez nos frutos pré-tratados com ácido cítrico e ácido ascórbico em relação ao valor inicial, que se refletiu na diminuição da relação sólidos solúveis/acidez total titulável. O tratamento com ácido ascórbico foi o único a proporcionar aumento significativo na quantidade de vitamina $\mathrm{C}$ das fatias de kiwi. 
Os valores calculados para a diferença total de cor (ÄE*), após os pré-tratamentos, apresentaram-se estatisticamente diferentes entre si ao nível de $5 \%$ de significância no teste de Tukey. A maior variação total de cor foi verificada após o pré-tratamento das fatias em ácido cítrico, e o menor valor para o tratamento controle. As fatias de kiwi sofreram alterações nos parâmetros de cor ao longo do tempo de processamento osmótico, tornando-se mais escuras (diminuição de $L^{*}$ ), menos verdes (aumento de $a^{*}$ ) e menos amarelas (diminuição de $b^{\star}$ ). As amostras do tratamento controle sofreram as maiores variações na luminosidade $L^{*}$, já as fatias pré-tratadas com cloreto de cálcio foram as que melhor mantiveram a cor original do kiwi.

Para a determinação do modelo cinético da perda da cor instrumental das fatias de kiwi osmoticamente desidratadas foram utilizados os parâmetros de cor $\mathrm{a}^{*} \mathrm{e}$ da variação total de cor (ÄE*). A variação no parâmetro $a^{*}$, que define o componente verde e evidencia a degradação dos pigmentos de clorofila ao longo do processo, foi avaliada segundo o modelo de primeira ordem linearizado (Figura 1).

Na Tabela 2 são apresentados os parâmetros cinéticos e estatísticos da variação de $a^{*}$ nas fatias de kiwi durante a desidratação osmótica. Com base nos valores de $\mathrm{R}^{2}$ obtidos pode-se afirmar que os ajustes dos dados experimentais são adequados para estimar os parâmetros.

\section{FIGURA 1 - MODELO CINÉTICO DE PRIMEIRA ORDEM DA VARIAÇÃO DO PARÂMETRO DE COR $a^{*}$ EM FATIAS DE KIWI DURANTE A DESIDRATAÇÃO OSMÓTICA}

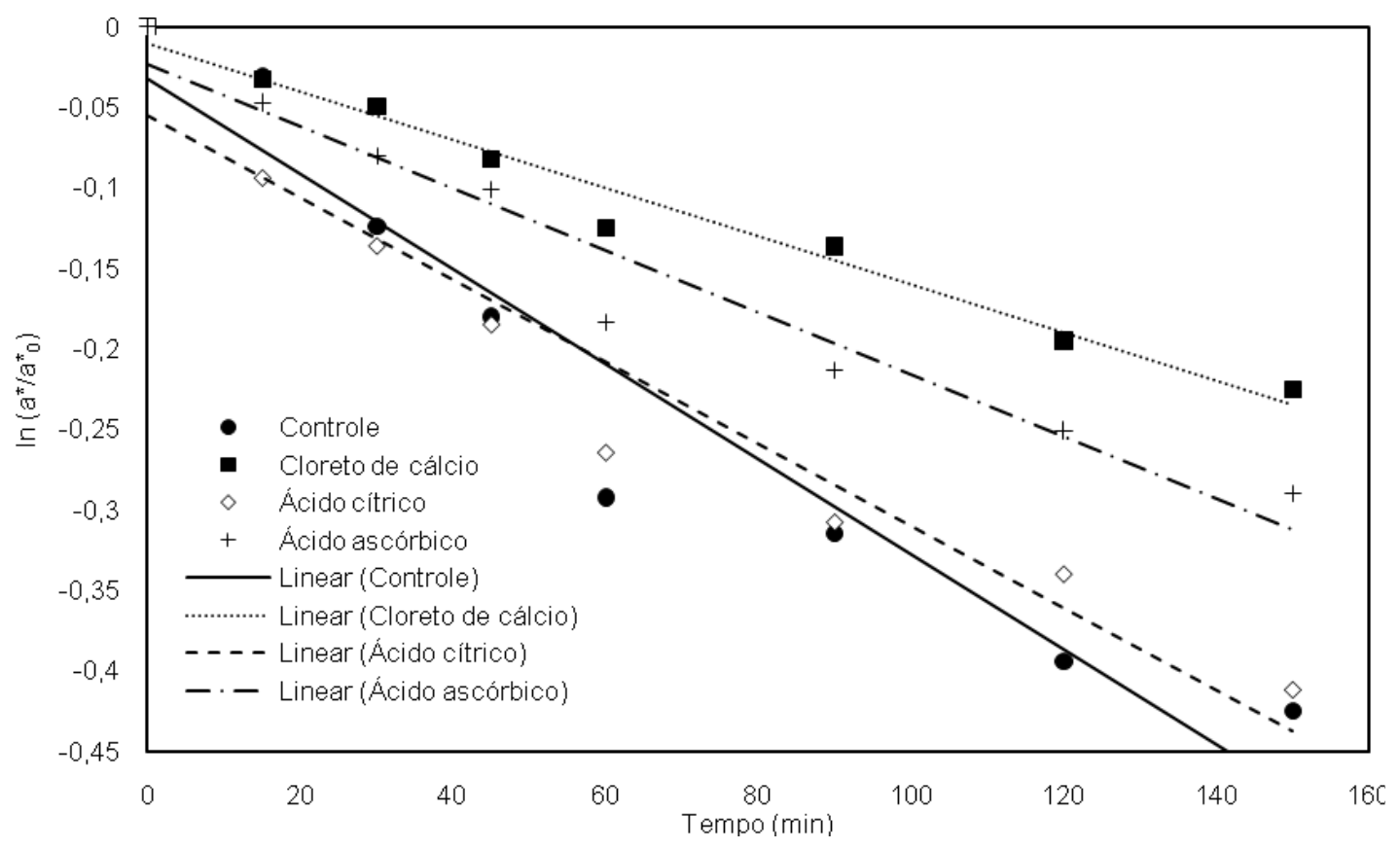

A ação do cálcio na preservação da cor pode ser explicada pelo fato de que a adição de sais, como o sódio, magnésio ou cálcio no processamento de vegetais verdes diminui a formação de feofitina (produto da degradação da clorofila). Tal reação é atribuída ao campo eletrostático protetor dos sais. A adição de cátions neutraliza a carga superficial negativa de proteína e ácidos graxos nas membranas dos cloroplastos e reduz a atração dos íons de hidrogênio para a superfície das membranas (NAKATANI, BARBER e FORRESTER, 1979).

Na desidratação osmótica de kiwis por 3,5 horas com solução de sacarose a $62^{\circ}$ Brix e $40^{\circ} \mathrm{C}$, VIAL, GUILBERT e CUQ (1991) observaram diminuição de $a^{\star}$ em relação à fruta fresca. Tal diminuição também foi verificada por BUCHWEITZ (2005). 


\section{TABELA 2 - PARÂMETROS CINÉTICOS E ESTATÍSTICOS DA VARIAÇÃO DE $a^{*}$ EM FATIAS DE KIWI DURANTE A DESIDRATAÇÃO OSMÓTICA}

\begin{tabular}{lcccc}
\hline \multirow{2}{*}{$\begin{array}{c}\text { PRÉ- } \\
\text { TRATAMENTO }\end{array}$} & \multicolumn{2}{c}{ PARÁMETROS CINÉTICOSDE } & \multicolumn{2}{c}{ PARÁMETROS } \\
\cline { 2 - 5 } & \multicolumn{2}{c}{ PRIMEIRA ORDEM } & \multicolumn{2}{c}{ ESTIISTICOS } \\
\hline Controle & 0,0030 & $\mathrm{t}_{10}(\mathrm{~min})$ & $\mathrm{R}^{2}(\%)$ & $\mathrm{P}(\%)$ \\
\hline Cloreto de cálcio & 0,0015 & 231 & 92,77 & $<5$ \\
\hline Ácido cítrico & 0,0025 & 462 & 97,80 & $<5$ \\
\hline Ácido ascórbico & 0,0019 & 277,20 & 93,92 & $<5$ \\
\hline
\end{tabular}

As fatias de kiwi perderam a cor verde durante o processamento com o aumento nos valores de $a^{\star}$, fato comprovado pela verificação da tonalidade esverdeada na solução osmótica ao final do processo. BUCHWEITZ (2005), analisando os parâmetros de cor no xarope residual também constatou a difusão do pigmento verde do kiwi para a solução.

De acordo com VIAL, GUILBERT e CUQ (1991), a variação na cor das fatias de kiwi decorre da concentração de clorofila, cujos pigmentos hidrofóbicos permanecem nos cloroplastos e não se difundem para a solução osmótica. Conforme FENEMA (1996), a clorofila pode sofrer alterações químicas gerando compostos de cor verde com maior solubilidade em água. Estas alterações podem ter ocorrido em virtude da ação da enzima clorofilase devido aos ácidos presentes na própria fruta, ou pelo abaixamento do $\mathrm{pH}$ com os pré-tratamentos ácidos.

O uso de pré-tratamentos químicos na desidratação osmótica do kiwi influenciou a variação total da cor das amostras analisadas. Na Figura 2 verifica-se que o ajuste dos valores da variação relativa $\left(\ddot{A} E^{\star} / \ddot{A} E^{\star} 0\right)$ seguiu o modelo cinético de primeira ordem. A análise dos dados da Tabela 3 torna evidente a relação direta entre a redução dos valores das constantes de reação com a diminuição da variação total da cor ( $\left(\ddot{E} E^{\star}\right)$. O menor efeito de mudança na coloração durante o processo foi verificado no pré-tratamento com ácido cítrico, com constante de reação de $0,0042 \mathrm{~min}^{-1} \mathrm{e}$ tempo de meia-vida de 165 minutos.

FIGURA 2 - MODELO CINÉTICO DE PRIMEIRA ORDEM DA VARIAÇÃO TOTAL DE COR EM FATIAS DE KIWI DURANTE A DESIDRATAÇÃO OSMÓTICA

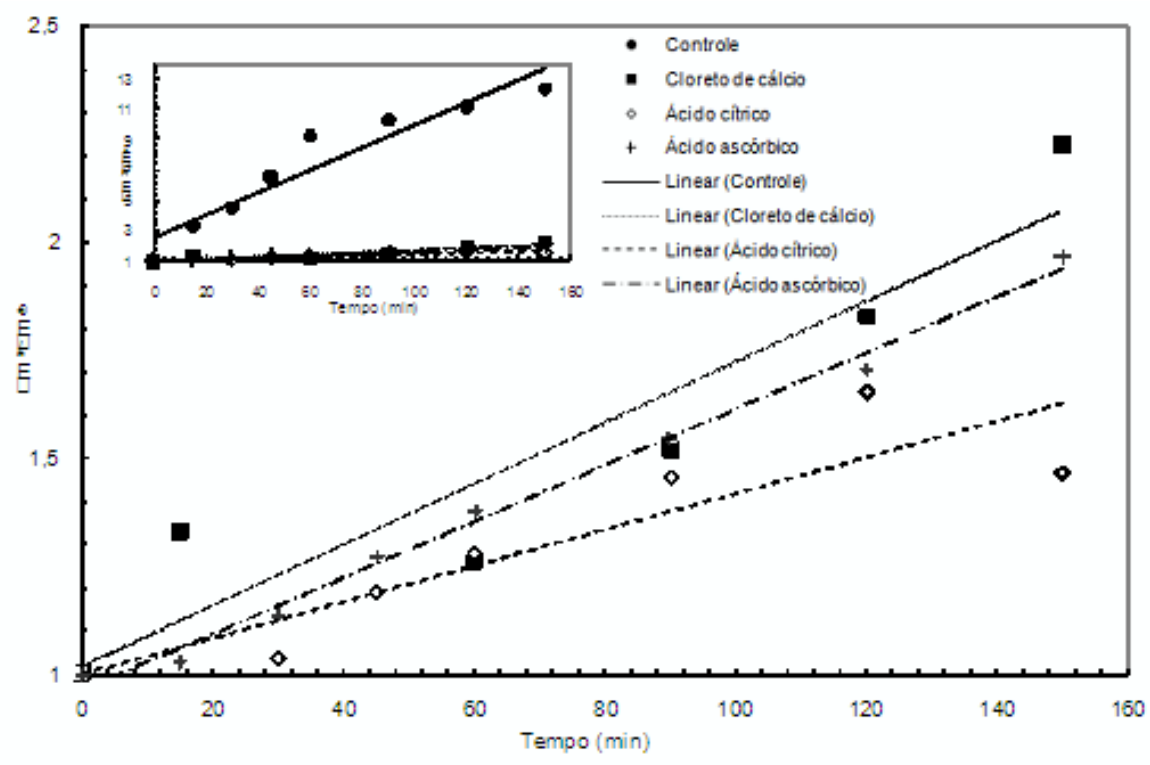




\section{TABELA 3 - PARÂMETROS CINÉTICOS E ESTATÍSTICOS DA VARIAÇÃO TOTAL DE COR EM FATIAS DE KIWI DURANTE A DESIDRATAÇÃO OSMÓTICA}

\begin{tabular}{lcccc}
\hline \multirow{2}{*}{ PRÉ-TRATAMENTO } & \multicolumn{2}{c}{ PARÁMETROS CINÉTICOS DE } & \multicolumn{2}{c}{ PARÁMETROS } \\
& \multicolumn{2}{c}{ PRIMEIRA ORDEM } & \multicolumn{2}{c}{ ESTISTCOS } \\
\cline { 2 - 5 } & $\mathrm{k}\left(\mathrm{min}^{-1}\right)$ & $\mathrm{t}_{1 / 2}(\mathrm{~min})$ & $\mathrm{R}^{2}(\%)$ & $\mathrm{P}(\%)$ \\
\hline Controle & 0,0739 & 9,37 & 90,19 & $<5$ \\
\hline Cloreto de cálcio & 0,007 & 99 & 87,84 & $<5$ \\
\hline Ácido cítrico & 0,0042 & 165 & 81,68 & $<5$ \\
\hline Ácido ascórbico & 0,0065 & 106,61 & 99,28 & $<5$ \\
\hline
\end{tabular}

\subsection{VITAMINA C}

Observou-se (Tabela 4) queda significativa no teor de vitamina $\mathrm{C}$ nos primeiros 30 minutos de processamento, mas a partir de 45 minutos não se verificou decréscimo importante. Ao final da desidratação osmótica, os maiores teores de vitamina $C$ foram encontrados nas fatias submetidas aos pré-tratamentos com ácido ascórbico e ácido cítrico, respectivamente. Tal fato pode estar relacionado com a absorção desses ácidos pelos tecidos da fruta durante o tempo de imersão. Constatou-se perda média de $40 \%$ do conteúdo inicial, sendo que o tratamento controle proporcionou a menor retenção do nutriente nas fatias de kiwi ao término do processo osmótico.

\section{TABELA 4 - TEORES DE VITAMINA C EM FATIAS DE KIWI DURANTE A DESIDRATAÇÃO OSMÓTICA}

\begin{tabular}{|c|c|c|c|c|c|c|c|c|}
\hline \multirow[b]{3}{*}{$\begin{array}{l}\text { TEMPO } \\
\text { (min) }\end{array}$} & \multicolumn{8}{|c|}{ PRÉ-TRATAMENTO QUIMMICO } \\
\hline & CONT & OLE & CLORETO & ECÁLCIO & ÁCIDO & TRICO & ÁCIDO AO & CÓRBICO \\
\hline & $\begin{array}{l}\text { Vitamina C } \\
(\mathrm{mg} / 100 \mathrm{~g})\end{array}$ & $\begin{array}{c}\text { Retenção } \\
\text { de } \\
\text { vitamina } \\
\mathrm{C}(\%)\end{array}$ & $\begin{array}{l}\text { Vitamina C } \\
(\mathrm{mg} / 100 \mathrm{~g})\end{array}$ & $\begin{array}{c}\text { Retençẫo } \\
\text { de } \\
\text { vitamina } \\
C(\%)\end{array}$ & $\begin{array}{l}\text { Vitamina C } \\
(\mathrm{mg} / 100 \mathrm{~g})\end{array}$ & $\begin{array}{c}\text { Retençẫo } \\
\text { de } \\
\text { vitamina } \\
\mathrm{C}(\%)\end{array}$ & $\begin{array}{l}\text { Vitamina C } \\
(\mathrm{mg} / 100 \mathrm{~g})\end{array}$ & $\begin{array}{c}\text { Retençẫo } \\
\text { de vitamina } \\
\text { C (\%) }\end{array}$ \\
\hline 0 & $135,2^{2^{\mathrm{B}}}$ & 100,0 & $13977^{\text {at }}$ & 100,0 & $143,60^{a^{\mathrm{B}}}$ & 100,0 & $180,1^{a^{A}}$ & 100,0 \\
\hline 15 & $1095^{\mathrm{ab} A}$ & 810 & $125,9^{\text {abA }}$ & 90,1 & $1287^{\mathrm{abA} A}$ & 896 & $154,2^{\mathrm{abA} A}$ & 856 \\
\hline 30 & $101,5^{\mathrm{mct}}$ & 75,1 & 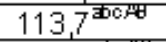 & 813 & $118,3^{\text {क्ये }}$ & 824 & $143,9^{\text {क्ल }}$ & 799 \\
\hline 45 & $94,72^{\mathrm{bcB}}$ & 70,1 & $102,95^{\mathrm{bCH} H}$ & 737 & $98,13^{\mathrm{bCAB}}$ & 683 & $1358^{\mathrm{bCA}}$ & 754 \\
\hline 60 & $822 b^{\mathrm{ct}}$ & 608 & $93,3^{6 \mathrm{CH}}$ & 668 & $96,6^{\mathrm{bct}}$ & 673 & $137^{\mathrm{BCA}}$ & 76,1 \\
\hline 90 & $786 b^{6 \theta}$ & 58,1 & $85,2^{\mathrm{cB}}$ & 610 & $92,8^{\mathrm{bet}}$ & 646 & $130^{\mathrm{bCA}}$ & 722 \\
\hline 120 & $72,45^{\mathrm{ct}}$ & 536 & $82,65^{\mathrm{cB}}$ & 59,1 & $95,3^{\mathrm{bct}}$ & 66,4 & $125^{\mathrm{bCA}}$ & 69,4 \\
\hline 150 & $74,13^{\mathrm{bc \theta}}$ & 548 & $8190^{\circ \theta}$ & 586 & $91,37^{\mathrm{CAB}}$ & 636 & $112,4^{\mathrm{CA}}$ & 62,4 \\
\hline
\end{tabular}

Para BUCHWEITZ (2005) e VIAL, GUILBERT e CUQ (1991), que trabalharam com solução de sacarose a $65^{\circ} \mathrm{Brix}$ a $40^{\circ} \mathrm{C}$ e solução de $62^{\circ} \mathrm{Brix}$ a $40^{\circ} \mathrm{C}$, respectivamente, as perdas de ácido ascórbico durante o processo representaram aproximadamente um terço do conteúdo inicial. $\mathrm{ABUGOCH}$ e GUARDA (1991) processaram fatias de kiwi de $7 \mathrm{~mm}$ de espessura, usando suco concentrado de maçã como agente osmótico (70,5\% de sólidos solúveis a 1500 rpm). Verificaram perdas de 58, 65 e $70 \%$ a $30^{\circ} \mathrm{C}$, atribuídas à lixiviação para os tempos de 60,120 e 180 minutos respectivamente.

Conforme VIAL, GUILBERT e CUQ (1991), as perdas de ácido ascórbico durante o processo osmótico podem ocorrer basicamente pela sua difusão para a solução desidratante ou pela degradação térmica. Considerando que no presente estudo utilizou-se temperatura relativamente baixa é provável que tenha predominado o processo de difusão da vitamina $C$ para a solução osmótica.

A reação de degradação do ácido ascórbico em produtos de frutas pode formar compostos 
que ao se combinarem com aminoácidos resultam na formação de produtos de cor escura, vindo a prejudicar diretamente a coloração do alimento (ESKIN, 1990; LARISCH, GROB e PISCHETSRIEDER, 1998; BURDURLU, KOCA e KARADENIZ, 2006).

\subsection{RELAÇÃO ENTRE COR INSTRUMENTAL E TEOR DE VITAMINA C}

Com a finalidade de correlacionar os resultados da cor instrumental com os teores de vitamina $\mathrm{C}$ ao longo do processo foram ajustados os valores do logaritmo das variações relativas da concentração de vitamina $\mathrm{C}$ e cromaticidade ${ }^{\star}$ (Figura 3 ).

\section{FIGURA 3 - CORRELAÇÃO ENTRE COR INSTRUMENTAL ( $\left.a^{*} / a^{*} 0\right)$ e TEOR DE VITAMINA C $\left(A / A_{0}\right)$ DAS FATIAS DE KIWI DURANTE A DESIDRATAÇÃO OSMÓTICA}

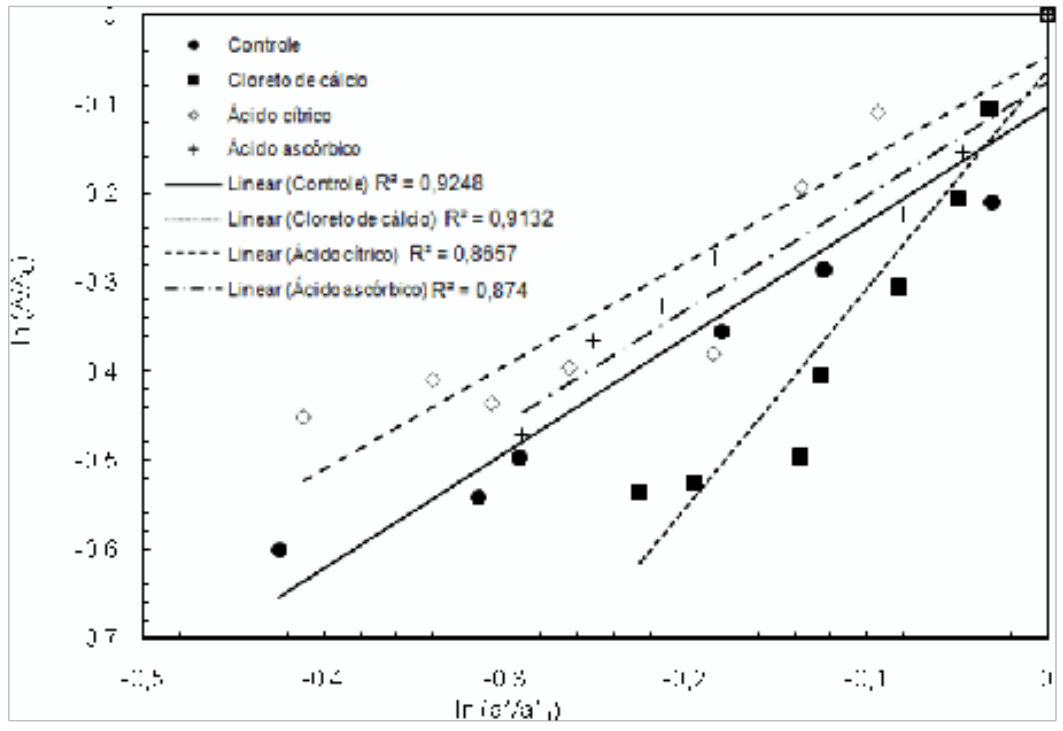

Com base nos valores dos coeficientes de correlação $\left(R^{2}\right)$ pode-se verificar a influência do uso de pré-tratamentos químicos nas características de cor e do teor de vitamina $\mathrm{C}$ na desidratação osmótica das fatias de kiwi.

\section{CONCLUSÃO}

Houve aumento nos valores de cromaticidade $a^{*}$ das fatias de kiwi, sendo essa variação ajustada ao modelo cinético de primeira ordem. O pré-tratamento com cloreto de cálcio evidenciou melhor manutenção da cor verde durante o processo. Os pré-tratamentos utilizados mostraram efeito significativo na diminuição da variação total de cor das fatias de kiwi.

A perda de ácido ascórbico ocorreu em maior intensidade nos primeiros 30 minutos de processo e pode ser atribuída à difusão da vitamina $\mathrm{C}$ para a solução osmótica. Aabsorção do ácido cítrico e do ácido ascórbico pelos tecidos da fruta durante o pré-tratamento resultou em maior retenção da vitamina $\mathrm{C}$ ao final da desidratação.

\section{ABSTRACT}

\section{COLOR AND ASCORBIC ACID DEGRADATION ON OSMOTIC DEHYDRATED KIWIFRUIT}

This work studied color and ascorbic acid degradation on osmotic dehydration of kiwifruit. The fruits, submitted to three kinds of chemical pretreatments (calcium chloride, citric acid and ascorbic acid) were dehydrated 
with sucrose solution at $50^{\circ}$ Brix during 150 minutes in a thermostatic bath at $40^{\circ} \mathrm{C}$ under agitation of $70 \mathrm{rpm}$. The parameters degradation reactions $\mathrm{a}^{*}$ and total color variation $\left(\Delta \mathrm{E}^{\star}\right)$ presented the best fit on first order kinetic model. The pretreatment with calcium chloride propitiated better maintenance of the green color of kiwifruit slices during the process. Vitamin C values presented average losses of about $40 \%$ until the end of dehydration. Citric and ascorbic acid treatments propitiated the highest vitamin $\mathrm{C}$ levels maintenance of kiwifruit slices.

KEY-WORDS: KIWIFRUIT; OSMOTIC DEHYDRATION; COLOR; ASCORBIC ACID, DEGRADATION.

\section{REFERÊNCIAS}

1 ABUGOCH, J. L.; GUARDA, M. A Estudio de la perdida de acido ascorbico total en rodajas de kiwi durante la deshidratación osmotica. Alimentos, Santiago, v. 16, n. 5, p. 15-17, 1991.

2 AOAC. Association of Official Analytical Chemists. Official methods of analysis of AOAC International. $14^{\text {th }}$ ed. Washington, 1984.

3 BUCHWEITZ, P. R. Avaliação da pré-secagem osmótica de kiwi (Actinidia deliciosa) complementada por processos convencionais. Campinas, 2005. 223 f. Tese (Doutorado em Tecnologia de Alimentos) - Faculdade de Engenharia de Alimentos - Universidade Estadual de Campinas.

4 BURDURLU, H. S.; KOCA, N.; KARADENIZ, F. Degradation of vitamin C in citrus juice concentrates during storage. Journal of Food Engineering, v. 74, p. 211-216, 2006.

5 CARVALHO, A. V.; LIMA, L. C. de O. Qualidade de kiwis minimamente processados e submetidos a tratamento com ácido ascórbico, ácido cítrico e cloreto de cálcio. Pesquisa Agropecuária Brasileira, Brasília, v. 37, n.5, p. 679-685, 2002.

6 DECAGON DEVICES. Water activity for food science: assuring safety, quality and governamental compliance. 2007. Disponível em: <http://www.decagon.com/> Acesso em: 08 de jun. de 2007.

7 ESKIN, N. A. M. Biochemistry of food processing: browning reactions in foods. In: BIOCHEMISTRY of foods. $2^{\text {nd }}$ ed. Londres: Academic Press, 1990. p. 240-295.

8 FENEMA, O. R. Food Chemistry. $3^{\text {rd }}$ Madison: Marcel Dekker, 1996.

9 GORDON, L. R.; SAMANIEGO-ESGUERRA, M. C. Effect of soluble solids and temperature on ascorbic acid degradation in lemon juice stored in glass bottles. Journal of Food Quality, v. 13, p. 361-374, 1990.

10 GOULARTE, V.D.S.; ANTUNES, E.C.; ANTUNES, P.L. Qualidade de maçã Fuji osmoticamente concentrada e desidratada. Ciência e Tecnologia de Alimentos, Campinas, v. 20, n.2, p. 160-163, 2000.

11 HUNTERLAB. Applications Note, v. 8, n. 7, 1996. Disponível em: <http://www.hunterlab.com> Acesso em: 14 de ago. de 2006.

12 IAL. Instituto Adolfo Lutz. Normas analíticas do Instituto Adolfo Lutz: métodos químicos e físicos para análise de alimentos. 3. ed. São Paulo, 1985. v. 1

13 IBARZ, A.; PAGÁN, J.; GARZA, S. Kinetic models of colour changes in pear puree during heating at relatively high temperatures. Journal of Food Engineering, n. 39, p. 415-422, 1999.

14 JOHNSON, J. R.; BRADDOCK, R. J.; CHEN, C. S. Kinetics of ascorbic acid loss and nonenzymatic browning in orange juice serum: experimental rate constants. Journal of Food Science, v. 3, n. 60, p. 502-505, 1995.

15 KLUTER, R. A.; NATTRESS, D. T.; DUNNE, C. P.; POPPER, R. D. Shelf life evaluation of cling peaches in retort pouches. Journal of Food Science, v. 54, n. 4, p. 849-864, 1994.

16 KOWALSKA, H.; LENART, A. Mass exchange during osmotic pretreatment of vegetables. Journal of Food Engineering, n. 49, p. 137-140, 2001.

17 LARISCH, B.; GROB, U.; PISCHETSRIEDER, M. On the reaction of L-ascorbic acid with propylamine under various conditions: quantification of the main products by HPLC/DAD. Zeitscrift fur Lebensmitel-Untersuchung UndForschung A, n. 206, p. 333-337, 1998.

18 LEE, H. S.; COATES, G. A. Vitamin C in frozen, fresh squeezed, unpasteurized, polyethylene-bottled orange juice: a storage study. Food Chemistry, v. 65, p. 165-168, 1999.

19 LOZANO, J. E; IBARZ, A. Colour changes in concentrated fruit pulp during heating at high temperatures. Journal of Food Engineering, v. 31, p 365-373, 1997. 
20 MARTIM, N. S. P. P. Estudo das características de processamento da manga (Mangifera indica L.) variedade Tommy Atkins desidratada. Curitiba, 2006. 76 f. Dissertação (Mestrado em Tecnologia de Alimentos) - Universidade Federal do Paraná.

21 MICHIGAN STATE UNIVERSITY. MSTAT-C - versão 2.10. East Lansing, MI, 1989. 2 disquetes.

22 MOTOHASHI, N.; SHIRATAKI, Y.; KAWASE, M.; TANI, S.; SAKAGAMI, H.; SATOH, K.; KURIHARA, T.; NAKASHIMA, H.; MUCSI, I.; VARGA, A.; MOLNÁR, J. Cancer prevention and therapy with kiwifruit in Chinese folklore medicine: a study of kiwifruit extracts. Journal of Ethnopharmacology, v. 81, p. 357-364, 2002.

23 NAKATANI, H. Y.; BARBER, J.; FORRESTER, J. A. Surface charges on chloroplast membranes as studied by particle electrophoresis. Biochimica et Biophysica Acta, v. 504, p. 215-225, 1979.

24 SINGH, R. P. Computer applications in food technology: use of spreadsheets in graphical, statistical, and process analyses. San Diego: Academic Press, 1996.

25 SOUZA, P. V. D.; MARODIN, G. A. B.; BARRADAS, C. I. N. Cultura do quivi. Porto Alegre: Cinco Continentes, 1996. $104 \mathrm{p}$.

26 TACO. Tabela brasileira de composição de alimentos. Campinas: NEPA-UNICAMP, 2004.42 p.

27 TRICHES, D.; SEBBEN, M. Análise da cultura do kiwi e seu papel para o desenvolvimento da Região de Farroupilha - RS - 1999/2000. Disponível em: <http://hermes.ucs.br/ccea/ipes/Textosparadiscussao.html> Acesso: em 10 de jan. 2007.

28 USDA. United States Department of Agriculture. National nutrient database for standard reference. Release 17 (2004). Disponível em: <http://www.nal.usda.gov/fnic/foodcomp/cgi-bin/list_nut_edit.pl> Acesso em: 20 jan. 2006.

29 VIAL, C.; GUILBERT, S.; CUQ, J. L. Osmotic dehydration of kiwi fruits: influence of process variables on the color and ascorbic acid content. Science des Aliments, Paris, v. 11, p. 63-84, n. 1, 1991.

30 VILAS BOAS, E. V. de B. Tecnologia de processamento mínimo de banana, mamão e kiwi. In: SEMINÁRIO INTERNACIONAL DE PÓS-COLHEITAE PROCESSAMENTO MÍNIMO DE FRUTAS E HORTALIÇAS, 2002, Brasília. Anais... Brasília: Embrapa, 2002. p. 1-7. 